\title{
ASSOCIATION MAPPING OF FIBER AND AGRONOMIC CHARACTERS IN EGYPTIAN COTTON (Gossypium
} barbadense L.) GENOTYPES

Ismail, M. 1; K. F. M. Salem²; A. M. El-Zanaty' and R.M. Esmail ${ }^{3}$

${ }_{1}^{1}$ Genetic Dept, Fac. of Agric., Minufiya Univ., Shibin El-Kom, Egypt

2Plant Biotechnology Dept., Genetic Engineering and Biotechnology

Res. Institute (GEBRI), Minufiya Univ., Egypt

${ }^{3}$ Genetics and Cytology Dept., National Res. Center (NRC), Dokki, Cairo, Egypt

\begin{abstract}
In this study the extent of linkage disequilibrium (LD) and association mapping of fiber and agronomic characters is assessed using 11 Egyptian cotton genotypes and 116 random amplified polymorphic DNA markers (RAPDs). The studied genotypes, using Bayesian algorithm, showed weak population structure and were assigned to three admixed clusters. Additionally, high level of relatedness was observed conforms to full- and half-sibs relationship. The LD showed slow decay with distance $(<50 \mathrm{cM})$. The population structure and relatedness are considered while conducting association mapping. Consequently, the Unified Mixed Model approach was used to account for population/family structures by inclusion of population structure $(Q)$ and kinship $(K)$ matrices. With such considerations, a total of five significant associations were observed between RAPD and agronomic characters. Among these associations single RAPD marker concurrently associated with three traits. These findings highlight the potential of association mapping in Gossypium barbadense considering population and family structure. Also the co-association would accelerate the marker assisted section (MAS) programs as a single marker could be utilized to breed for multiple correlated traits.
\end{abstract}

Keywords: Cotton (Gossypium barbadense L.); association mapping; RAPD marker; linkage disequilibrium (LD).

\section{INTRODUCTION}

The genus, Gossypium encompasses about 50 species of trees, shrubs and herbs (Fryxell 1971), which also includes four cultivated species; G. arboreum, G. herbaceum, G. hirsutum and G. barbadense. Additionally, it considers the lead textile fibre crop and is the second most important oil seed crop in many continents (Cherry and Leffler 1984). Cotton is a renewable source of natural fiber and recently cotton breeders have placed efforts in increasing yield and quality (Zhang et al. 2012). Agronomic and fiber quality are usually complex traits. The determination of association between complex traits and genetic markers for important characteristics increase the efficiency in selection through the use of marker-assisted selection (MAS) (Akash 2003). With the accelerating advances in molecular genetic markers, it becomes feasible to associate genomic regions containing these markers to complex traits variants (Hall et al. 2010). It is expected that association mapping (also known as linkage disequilibrium mapping) studies will provide high resolution mapping compared to traditional QTL mapping where the 
latter utilize limited parental populations resulting in less variable offspring. Association mapping is being utilized to dissect complex traits in many strategic grain crops (wheat; Mir et al. 2012, maize, rice; Famoso et al. 2011); however, cotton (Gossypium spp.) as a main fiber crop is receiving less attention although its planted area expected to reach 30 million hectare worldwide (USDA 2010). The narrow genetic background of the present cotton varieties particularly in Egypt (El-Zanaty et al. 2011) due to extensive breeding programs is the most concern of cotton breeders as it might lead to decline in cotton yield and quality (Van Esbroeck 1999; Hollis 2004). Many factors influence the reduction in cotton yield and quality mainly associated with the loss of genetic diversity due to selection pressure of domestication (lqbal et al 2001). Additionally, the complexity of cotton genome conceded as a major hurdle in understanding the gene-traits interactions (Abdurakhmonov et al. 2008). As a result it is essential to explore novel genetic resources combined with the application of new genomic tools to understand gene-trait associations (Abdurakhmonov et al. 2008). Association mapping hence provide insight into marker-trait associations in cotton. Most of associations mapping studies in cotton are limited (Abdurakhmonov et al. 2007) and mainly focus on Gossypium arboretum (Kantartzi et al. 2008) and Gossypium hirsutum (Abdurakhmonov et al. 2008) with no similar studies are conducted on $G$. barbadense relative to its importance worldwide (it accounts for about $9 \%$ of the world's cotton production; Poehlman and Sleper 1995). Therefore such studies are important for cotton breeding programs aimed to enhance economically important traits. The accuracy of association studies manly relies on the level of linkage disequilibrium (LD) among loci, which is poorly examined in cotton. So, understanding the level of LD and marker-trait associations would provide valuable genetic markers that facilitate markers assisted cotton breeding. Deciphering the genetic architecture of complex traits have long been the ultimate goal of many plant breeders. In this context, it is essential to dissect the phenotypic variation within and among individuals with known relatedness (Lynch and Walsh 1998). Early LD studies in different crop species suggested that association mapping might significantly improve the fine mapping of QTL (Kantartzi et al. 2008). Although association mapping is emerging as an alternative approach in dissecting complex traits, but it is also associated with potential limitations (Hall et al. 2010). The presence of population and family structures (FlintGarcia et al. 2003; Voight and Pritchard 2005) are considered major hurdles in this approach and should be accounted for while conducting association mapping to avoid unauthentic marker-trait associations (Lander and Schork 1994). To overcome population and/or kinship structures drawbacks, several association genetics methods were developed and successfully implemented (e.g. Marchini et al. 2001; Thornsberry et al. 2001). The newly development "Unified Mixed Model (UMM)" (Yu et al. 2006) is an advance in association mapping research as it offers a simple method where both population and family structures are accounted for during data analyses. The current study aimed to assess the genetic association between RAPD markers and fiber and agronomic traits in Egyptian cotton (Gossypium barbadense L.) genotypes. 


\section{MATERIALS AND METHODS}

\section{Plant material, characters, and RAPD markers}

A sample of 11 Egyptian cotton genotypes: Ashmony, Dandara, Giza45, Giza70, Giza75, Giza76, Giza77, Giza80, Giza85, Giza88, and Giza89 were used in this study. Three fiber traits (fiber length, fiber fineness, and fiber strength) and five agronomic traits (number of bolls, boll weight, seed yield, lint yield, and lint percentage) were measured in a randomised complete block design with three replicates. Units of measure, minimum, maximum, average and standard deviation for each character are provided in Table 1 (for details, see El-Zanaty et al. 2011). The studied genotypes were previously genotyped using 19 random RAPD markers (El-Zanaty et al. 2011), which provided a total of 116 fragments; each fragment will be considered as an independent marker in the association study.

Table 1: Fiber and agronomic characters used in the current study. The minimum, maximum, average, and standard deviation of each character are indicated.

\begin{tabular}{|c|c|c|c|c|c|}
\hline Character & Units of measure & Minimum & maximum & Average & $\begin{array}{l}\text { Standard } \\
\text { deviation }\end{array}$ \\
\hline Number of bolls & & 10.520 & 15.430 & 12.613 & 1.704 \\
\hline Boll weight & Grams & 2.480 & 2.880 & 2.725 & 0.131 \\
\hline Seed yield & Grams & 28.110 & 43.960 & 34.402 & 5.181 \\
\hline Lint yield & Grams & 9.920 & 16.020 & 12.210 & 1.979 \\
\hline Lint \% & Percentage & 34.300 & 36.430 & 35.448 & 0.568 \\
\hline Fiber length & Centimetre & 30.030 & 35.430 & 32.259 & 2.020 \\
\hline Fineness & Mtex & 3.720 & 4.400 & 4.014 & 0.207 \\
\hline Strength ${ }^{<}$ & Grams/tex & 26.570 & 35.740 & 31.385 & 2.946 \\
\hline
\end{tabular}

Fineness is linear density or weight per unit length of fibre; milligrams per kilometre (mtex).

${ }^{2}$ The strength is the breaking force required for a bundle of fibres of a given weight; the test value being a measure of breaking stress or tenacity, expressed in terms of grams per tex (g/tex).

Statistical analyses

\section{Linkage disequilibrium analysis}

Linkage disequilibrium (LD) measured as $r^{2}$ (Hill and Robertson 1968) which represent the correlation between all pairs of RAPD markers was estimated using the program TASSEL version 3 (Bradbury et al. 2007). The LD decay with physical distance in centimorgan (cM) between all pairs of RAPD markers will be plotted.

\section{Population structure and kinship assessment}

To determine population structure, the Bayesian algorithm as implemented in STRUCTURE 2.3.2 (Hubisz et al. 2009) was used with an admixture model and correlated allele frequencies to determine number of groups (i.e., clusters). The presumed number of clusters $(K)$ varied between one and seven. The program ran with a burn-in period of $10^{4}$ iterations followed by $10^{4}$ data collection iterations, and was replicated four times. The number of clusters was determined using the $\Delta K$ statistic (Evanno et al. 2005) based on the log likelihood values obtained from for each structure run. DISTRUCT 1.1 (Rosenberg 2004) was used to plot the probability of membership of each genotype in each cluster at the number of clusters $(K)$ 
that was best supported by $\Delta K$ approach. To assess the relatedness among cotton genotypes, the pairwise kinship coefficients among the studied genotypes were determined according to kinship procedure of Ritland 1996 that could be defined as:

$$
\theta_{i j}=\frac{Q_{i j}-Q_{m}}{1-Q_{m}},
$$

where $Q_{i j}$ the probability of identity in state for random genes from $i$ and $j$, and $Q_{m}$ the average probability of identity by state for genes coming from random individuals in the population from which $i$ and $j$ where drawn, using SPAGEDI (Hardy and Vekemans 2002). The the Q-matrix for the assignment of each genotypes to specific cluster and kinship matrix (K- matrix) 11 by 11 were used in mixed model association mapping.

Association mapping analysis

To determine putative associations between RAPD markers and traits under consideration we used the Unified Mixed Model (UMM, Yu et al. 2006) following equation:

$$
y=S \alpha+Q v+Z u+e,
$$

where $y, \alpha, v, u$, and $e$ are vectors of phenotypic observations, RAPD marker effect (fixed), population effect (fixed), kinship effect (random), and residual effect, respectively, and $S, Q, Z$ are incidence matrices of $1 \mathrm{~s}$ and 0 s relating $y$ to $\alpha, v$, and $u$, respectively. Association analysis were conducted using the TASSEL version 3 (Bradbury 2007), positive associations were determined at the nominal $0.05 \%$ level. The phenotypic variance explained by each marker $\left(R^{2}\right)$ is reported which represent the magnitude of the marker effect. Also, phenotypic effects represented by measuring units of each trait at the marker loci were calculated as differences between the means of the marker classes.

\section{RESULTS}

Analysis of linkage disequilibrium $\left(r^{2}\right)$ among polymorphic RAPD loci showed slow decay $\left(r^{2} \approx 0.11\right.$ within $\left.50 \mathrm{cM}\right)$ with few loci showing strong LD, $\left(r^{2}=1\right)$ (Figure 1). The log likelihood values across STRUCTURE runs using $\Delta K$ supported the presence of three clusters (the highest $\Delta K$ value obtained for $K=3$, Figure 2a). The STRUCTURE model-based analysis showed that the studied cotton genotypes were assigned to three highly admixed genetic backgrounds, the probability of membership of each genotype in the three identified cluster is indicated in Table 2. The first cluster included Ashmony, Dandra, Giza 75, Giza 76, and Giza 89, the second cluster included Giza 45, Giza 75, Giza 80, Giza 85 and Giza 88, and the third cluster harboured only Giza 77. The observed grouping did not show distinct differences among most of the genotypes except for Ashmony, Giza 45 and Giza 85, and Giza 77 where it assigned to cluster I, II, and III, respectively with high probability (proportion of membership $>0.80$; Table 1, Figure 2b). 
The pairwise kinship among the 11 genotypes resulted in the identification of high level of relatedness equivalent to half- and full-sib relationships, $25 \%$ and $50 \%$, respectively (Figure 3 ).

Association mapping analysis identified five significant marker-trait associations $(P<0.05)$ for three traits; number of bolls, lint yield, and seed yield with two RAPD loci number 22 and 43 (Table 3). RAPD locus number 22 associated with number of bolls and lint yield; however, RAPD locus 43 was associated with all three traits. The phenotypic variance $\left(R^{2}\right)$ explained by each marker was moderate and ranged between $51 \%$ and $57 \%$ for locus 22 with lint yield and number of bolls, respectively. Additionally, marker effect ranged between 2.9 and $10.4 \%$ for number of bolls and seed yield, respectively.

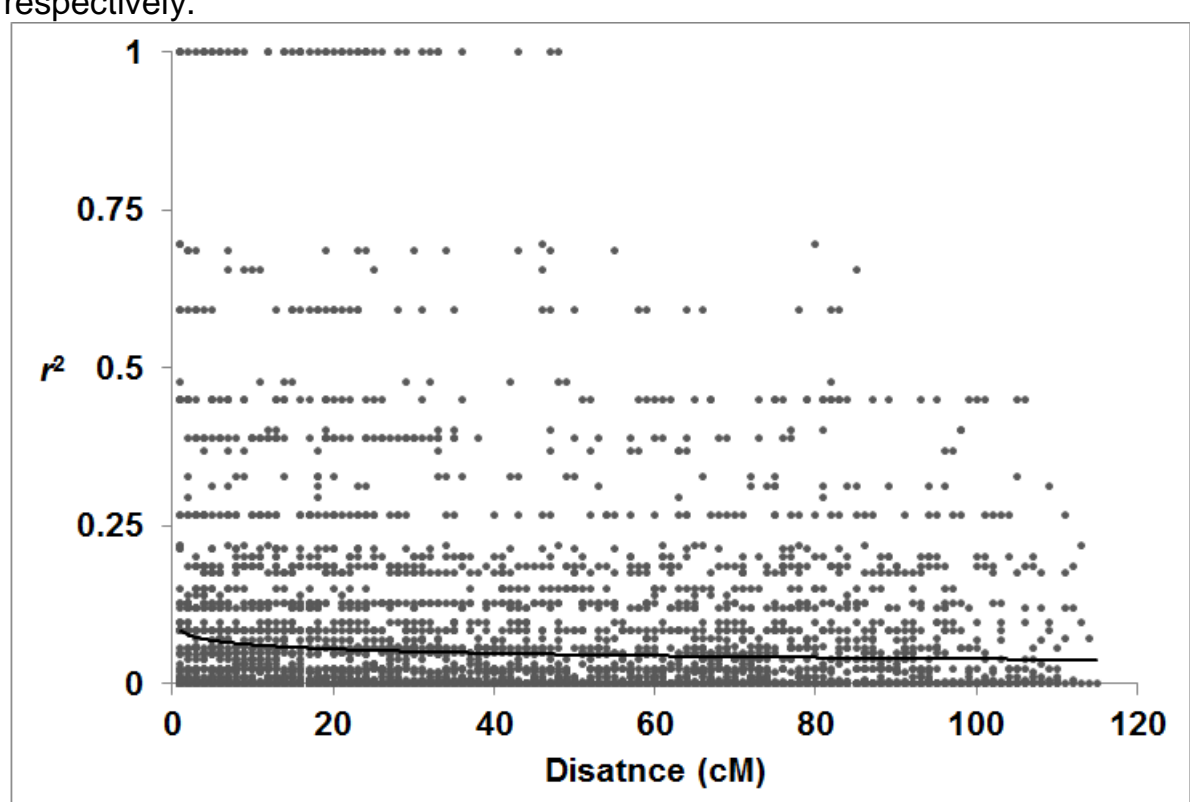

Figure 1: Plot of the squared correlations of allele frequencies $\left(r^{2}\right)$ versus distance in centimorgan (cM) between polymorphic markers in 11 Egyptian cotton genotypes. 
(a)

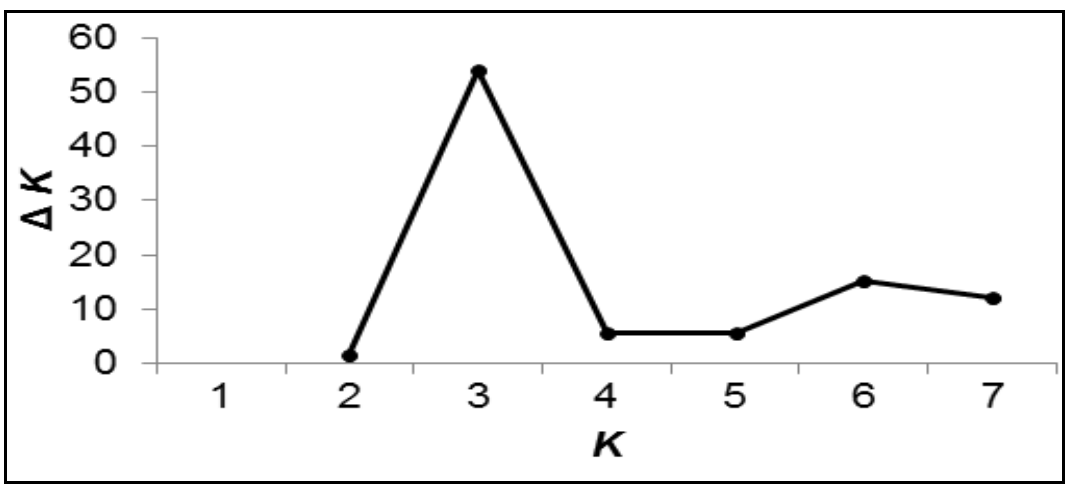

(b)
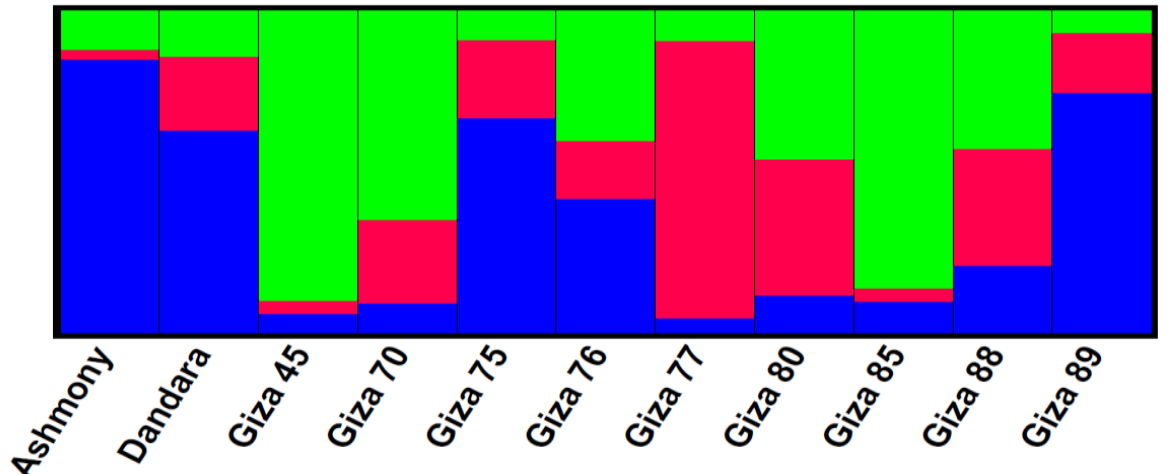

Figure 2: RAPD-based STRUCTURE analysis for 11 cotton genotypes: (a) magnitude of $\triangle K$ as a function of $K$, (b) distribution of STRUCTUREdefined groups among cotton genotypes for $K=3$, vertical lines represent membership probability for each genotype as output from DISTRUCT. Blue, red, and green colours represent cluster I, cluster II, and cluster III, respectively.

Table 2: Proportion of membership of each cotton genotype in STRUCTURE-defined clusters.

\begin{tabular}{lccc}
\hline Genotype & I & $\begin{array}{c}\text { Cluster } \\
\text { II }\end{array}$ & III \\
\hline Ashmony & $\mathbf{0 . 8 5 1}$ & 0.121 & 0.028 \\
Dandara & 0.629 & 0.143 & 0.228 \\
Giza45 & 0.060 & $\mathbf{0 . 8 9 9}$ & 0.041 \\
Giza70 & 0.092 & 0.649 & 0.259 \\
Giza75 & 0.668 & 0.09 & 0.242 \\
Giza76 & 0.418 & 0.403 & 0.18 \\
Giza77 & 0.046 & 0.092 & $\mathbf{0 . 8 6 2}$ \\
Giza80 & 0.115 & 0.460 & 0.425 \\
Giza85 & 0.098 & $\mathbf{0 . 8 6 3}$ & 0.04 \\
Giza88 & 0.208 & 0.427 & 0.365 \\
Giza89 & 0.747 & 0.067 & 0.186 \\
\hline
\end{tabular}

Number in bold represent proportion of membership $>0.80$ 


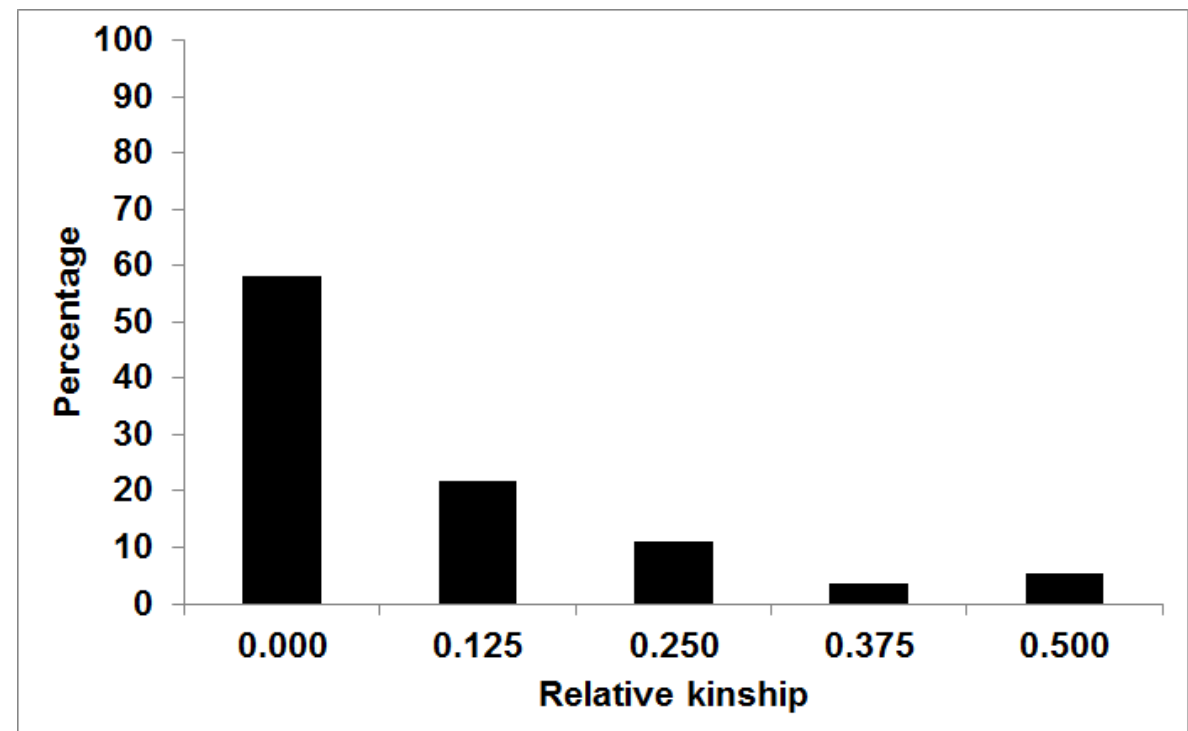

Figure 3: Distribution of pairwise kinship estimates among 11 cotton genotypes using genotypic data from 19 RAPD markers.

Table 3: Associations between RAPD markers and fiber and agronomic characters in cotton genotypes showing the RAPD marker number, its significance level $(P)$, its attributable \% of phenotypic variance $\left(\boldsymbol{R}^{2}\right)$, and marker effect.

\begin{tabular}{lcccc}
\hline \multicolumn{1}{c}{ Character } & RAPD marker & $\boldsymbol{P}$ - value & $\boldsymbol{R}^{2}$ & $\begin{array}{c}\text { Marker } \\
\text { effect }\end{array}$ \\
\hline \multirow{2}{*}{ Number of bolls } & 22 & $0.040^{*}$ & 0.575 & 2.926 \\
\multirow{2}{*}{ Boll weight } & 43 & $0.041^{*}$ & 0.567 & 3.463 \\
\hline Seed yield & 18 & 0.081 & 0.385 & 0.270 \\
Lint yield & 24 & 0.119 & 0.296 & 0.153 \\
\hline \multirow{2}{*}{ Lint \% } & 43 & $0.046^{*}$ & 0.534 & 10.405 \\
\hline \multirow{2}{*}{ Fiber length } & 22 & $0.049^{*}$ & 0.519 & 3.198 \\
& 43 & $0.042^{*}$ & 0.560 & 4.134 \\
\hline \multirow{2}{*}{ Fineness } & 18 & 0.053 & 0.495 & 1.291 \\
& 22 & 0.067 & 0.429 & 0.810 \\
\hline \multirow{2}{*}{ Strength } & 22 & 0.056 & 0.478 & 3.045 \\
*Significant marker-trait association $(\boldsymbol{P}<0.05)$ & 0.077 & 0.397 & 3.154 \\
\hline
\end{tabular}

${ }^{\star}$ Significant marker-trait association $(P<0.05)$.

\section{DISCUSSION}

Most association studies in plants have used populations representing global or regional diversity (Zhu et al. 2008) which can capture 
most of the genetic variability of a species. In the current study only Egyptian cotton varieties were utilized for two reasons; first the importance of Egyptian cotton varieties in producing an internationally recognized fiber quality and; second, using materials from existing breeding programs has an advantage that any favourable alleles identified will be present in the adapted genotypes. The presence of favourable allele in breeding programs will increase the efficiency of subsequent breeding plans. On the other hand, the breeding process might introduce new genetic structure, which can cause spurious associations (Stich et al. 2008). So, it is essential to understand the pattern of population structure, relatedness, and LD in the studied breeding materials so that the association method used is adequately account for them (Hamblin et al. 2010). The studied genotypes, as expected, showed low population structure pattern where STRUCTURE analysis indicated presence of three admixed groups. These genotypes probably share its genetic background at most of the studied markers, hence providing a mosaic pattern. These genotypes were mainly utilized for a long time as breeding resources in breeding programs. So, it appeared that the Egyptian cotton genotypes under consideration are lacking population structure probably due to extensive genetic improvement. Similar pattern of shared ancestry was also observed for a collection of exotic and domesticated Gossypium (Abdurakhmonov et al 2008) and for different accessions with different geographic origin (Kantartzi et al 2008). The clustering pattern observed herein and in other studies is indicative of a narrow genetic background of majority of the genus Gossypium. The lack of population structure is pronounced and call for prober consideration of the observed pattern while conducting association analysis. Population structure one of the major sources of false associations. In other words the association between a particular phenotype and a marker, without consideration of population structure would have a high rate of Type I error (false positive) as a result of spurious associations between non-linked loci (Kantartzi et al. 2008).

The level of LD decay observed in the current study was low with $r^{2}$ did not decay over long distance $(\approx 50 \mathrm{cM})$, indicating low recombination events at RAPD markers in Egyptian cotton germplasm. This pattern is in line with previous reports of slow LD decay in some cotton varieties, however, using nuclear microsatellites markers (Abdurakhmonov et al. 2008). Also, the observed pattern of LD in the current study was similar to that reported for barley (50 cM, Malysheva-Otto et al. 2006), sorghum (50 cM, Hamblin et al. 2004), and Arabidopsis (100 cM, Nordborg et al. 2002); however, our LD estimates was larger than those reported for wheat $(5 \mathrm{cM}$ Breseghello and Sorrells 2006) and sugar beet (3 cM; Kraft et al. 2000). Different factors affect level of LD among species. For instance; population structure, small effective population size, and inbreeding all increase the level of LD; whereas, larger effective population size and outcrossing may decrease the magnitude of LD (Gaut and Long 2003). So among these factors it appear that slow LD decay observed in the current study is attributable mainly to cotton mating system (mainly selfing with low out-crossing nature) and losing alleles due continues breeding efforts. This comes in line with the lack of population structure and high level of relatedness among the studied 
genotypes (relative kinship $>0.12$ in $20 \%$ of the genotype pairs). Similar findings of slow LD decay and high level of relatedness were also observed in G. hirsutum (Abdurakhmonov et al. 2008). The presence of slow LD decay among the studied loci in the cotton highlights the importance of surveying more loci for association mapping studies. It also suggests that genome scan is more suitable for association mapping studies compared to candid gene approach in cotton where LD extends over long distance as the situation in the current study. Association mapping intended to detect the extent to which gene-trait or genotype-phenotype differs together in a group of individuals relevant to linkage disequilibrium (Zondervan and Cardon 2004). Hence, highly correlated phenotypic traits are expected to be associated with the same molecular markers, hypothetically (Yan et al. 2009). In the current study association analysis revealed significant associations of single RAPD markers with three yield characters. The significance associations of RAPD marker 43 with number of bolls, lint yield and seed yield is noticeable and probably explained by significant correlations among characters $(r=0.9, p$ $<0.01$; El-Zanaty et al. 2011).

\section{CONCLUSIONS}

Application of association mapping to plant breeding appear to be a promising tool in overcoming limitations of conventional linkage mapping (Stich et al. 2005). Many factors affect the accuracy of association studies and should be considered while conducting such studies. Population structure and relatedness are the most of confounding factors. This highlights the proper consideration of population and/or family structure to avoid any bias that might arise from the presence of such factors. The results of the present study demonstrate weak population structure and presence of high degree of relatedness among Egyptian cotton genotypes. The level of LD decay with distance was low, conforming to selfing nature and loss of alleles due to extensive breeding. Association mapping revealed low marker-trait associations which probably associated with low sample size; however, it was adequate to investigate the statistical associations between RAPD and cotton yield traits. The absence of association between RAPD markers and fiber quality traits probably related to the complex inheritance of these traits and probably more loci are need to capture most of the genetic variability in fiber quality traits. The co-association is expected to improve breeding efficiency where a particular marker could be used to facilitate breeding for many traits.

\section{REFERENCES}

Abdurakhmonov IY, Buriev ZT, Saha S, Pepper AE, Musaev JA, Almatov A, Shermatov SE, Kushanov FN, Mavlonov GT and Reddy UK. (2007) Microsatellite markers associated with lint percentage trait in cotton, Gossypium hirsutum. Euphytica 156 141-156. 
Abdurakhmonov IY, Kohel RJ, Yu JZ. and Pepper AE. (2008). Molecular diversity and association mapping of fiber quality traits in exotic $G$. hirsutum L. germplasm. Genomics 92: 478-487

Akash M. (2003). Quantitative trait loci mapping for agronomic and Wber quality traits in upland cotton (Gossypium hirsutum L.) using molecular markers. Ph.D. dissertation, Louisiana State University, Baton Rouge, USA

Bradbury PJ, Zhang Z, Kroon DE and Casstevens TM. (2007). TASSEL: Software for association mapping of complex traits in diverse samples. Bioinformatics 23: 2633-2635

Breseghello F. and Sorrells ME. (2006). Association mapping of kernel size and milling quality in wheat (Triticum aestivum L.) cultivars.. Genetics 172: $1165-1177$

Cherry JP. and Leffler HR. (1984). Seed, In RJ Kohel, CF Lewis, eds, Cotton. ASA, Madison, Wisconsin, pp 511-569

El-Zanaty AM, Salem KFM. and Esmail RM. (2011). Detection of genetic diversity in Egyptian cotton (Gossypium barbadense L.) varieties using RAPD markers and morphological traits. J. Am. Sci. 7: 1107-1015

Evanno G, Regnaut S. and Goudet J. (2005). Detecting the number of clusters of individuals using the software STRUCTURE: a simulation study. Mol. Ecol. 14: 2611-2620

Famoso AN, Zhao K, Clark RT. and Tung C-W. (2011). Genetic architecture of aluminum tolerance in rice (Oryza sativa) determined through genome-wide association analysis and QTL mapping. PLoS Genet 7: e1002221

Flint-Garcia SA, Thornsberry JM. and Buckler ES. (2003). Structure of linkage disequilibrium in plants. Ann. Rev. Plant Biol. 54: 357-374

Fryxell PA. (1971). Phenetic analysis and the phylogeny of the diploid species of Gossypium L. (Malvaceae). Evolution 25: 554-562

Gaut BS. and Long AD. (2003). The lowdown on linkage disequilibrium. Plant Cell 15: 1502-1506

Hall D, Tegstrom C. and Ingvarsson PK. (2010). Using association mapping to dissect the genetic basis of complex traits in Plants. Briefings in functional genomics 9: 157-165.

Hamblin MT, Close TC, Bhat PR. and Chao S. (2010). Population structure and linkage disequilibrium in US barley germplasm: implications for association mapping. Crop Sci. 50:556-566

Hamblin MT, Mitchell SE, White GM. and Gallego J. (2004). Comparative population genetics of the panicoid grasses: sequence polymorphism, linkage disequilibrium and selection in a diverse sample of Sorghum bicolor. Genetics 167: 471-483

Hardy, O.J. and Vekemans X. (2002). SPAGeDi: a versatile computer program to analyse spatial genetic structure at the individual or population levels. Molecular Ecology Notes 2(4): 618-620

Hill WG. and Robertson A. (1968). Linkage disequilibrium in finite populations. Theor. Appl. Genet. 38:226-231 
Hollis PL. (2004). Cotton quality has declined over years. Southeast Farm Press.

http://southeastfarmpress.com/mag/farming_cotton_quality_declined.

Hubisz MJ, Falush D, Stephens M. and Pritchard J. (2009). Inferring weak population structure with the assistance of sample group information. Mol. Ecol. Res. 9: 1322-1332.

lqbal J, Reddy OUK, El-Zik KM. and Pepper AE. (2001). A genetic bottleneck in the 'evolution under domestication' of upland cotton Gossypium hirsutum L. examined using DNA fingerprinting. Theor. Appl. Genet. 103: $547-554$

Kantartzi SK. and Stewart JM. (2008). Association analysis of fibre traits in Gossypium arboreum accessions. Plant Breed. 127: 173-179

Kraft T, Hansen M. and Nilsson NO. (2000). Linkage disequilibrium and fingerprinting in sugar beet. Theor. Appl. Genet. 101: 323-326.

Lander ES. and Schork NJ. (1994). Genetic dissection of complex traits. Science 265:2037-2048.

Lynch M. and Walsh B. (1998). Genetics and Analysis of Quantitative Traits. Sinauer Associates, Inc., Sunderland

Malysheva-Otto LV, Ganal MW, and Röder MS. (2006). Analysis of molecular diversity, population structure and linkage disequilibrium in a worldwide survey of cultivated barley germplasm (Hordeum vulgare L.). BMC Genet. 7:6

Marchini J, Cardon LR, Phillips MS. and Donnelly P. (2001). The effects of human population structure on large genetic association studies. Nat. Genet. 36:512-517.

Mir RR, Kumar N, Jaiswal V. and Girdharwal N. (2012). Genetic dissection of grain weight in bread wheat through quantitative trait locus interval and association mapping. Mol. Breeding. DOI: 10.1007/s11032-011-9693-4

Nordborg M, Borevitz JO, Bergelson J, Berry CC. and Chory J. (2002). The extent of linkage disequilibrium in Arabidopsis thaliana. Nat. Genet. 30: 190-93

Poehlman, J. M., and Sleper D. A. (1995). Breeding field crops. Fourth Edition. lowa State University Press, USA $494 \mathrm{p}$.

Ritland K. (1996). Estimators for pairwise relatedness and individual inbreeding coefficients. Genet. Res. 67: 175-185.

Rosenberg N A. (2004). DISTRUCT: a program for the graphical display of population structure.

Stich B, Melchinger A.E., Frisch M., Maurer H.P., Heckenberger M. and Reif J.C. (2005) Linkage disequilibrium in European elite maize germplasm investigated with SSRs. Theor. Appl. Genet. 111: 723-730.

Stich B., Piepho H.-P., Mohring J., Heckenberger M., and Buckler E. S. (2008) Comparison of mixed-model approaches for association mapping. Genetics 178: 1745-1754.

Thornsberry JM, Goodman MM, Doebley J. and Kresovich S. (2001). Dwarf8 polymorphisms associate with variation in flowering time. Nat. Genet. 28: 286-289. 


\section{Ismail, M. et al.}

United States Department of Agriculture Foreign Agricultural Service Circular Series WAP 05-10 May 2010

Van Esbroeck GA, Bowman DT, May OL. and Calhoun DS.(1999). Genetic similarity indices for ancestral cotton cultivars and their impact on genetic diversity estimates of modern cultivars. Crop Sci. 9: 323-328.

Voight B.and Pritchard J. (2005). Confounding from cryptic relatedness in case-control association studies. PLoS Genet. 1:e32

Yan W, Li Y, Agrama H, Luo D. and Gao F. (2009). Association mapping of stigma and spikelet characteristics in rice (Oryza sativa L.). Mol. Breed. 24: 277-292

Yu JM, Pressoir G, Briggs WH. and Bi IV. (2006). A unified mixed-model method for association mapping that accounts for multiple levels of relatedness. Nat. Genet. 38: 203-208

Zhang K, Zhang J, Ma J. and Tang S. (2012). Genetic mapping and quantitative trait locus analysis of fiber quality traits using a threeparent composite population in upland cotton (Gossypium hirsutum L.). Mol. Breed. 29: 335-348

Zhu C, Gore M, Buckler ES. and Yu J. (2008). Status and prospects of association mapping in plants. Plant Genome 1:5-20

Zondervan KT. and Cardon LR. (2004). The complex interplay among factors that influence allelic association. Nat. Rev. Genet. 5:89-100

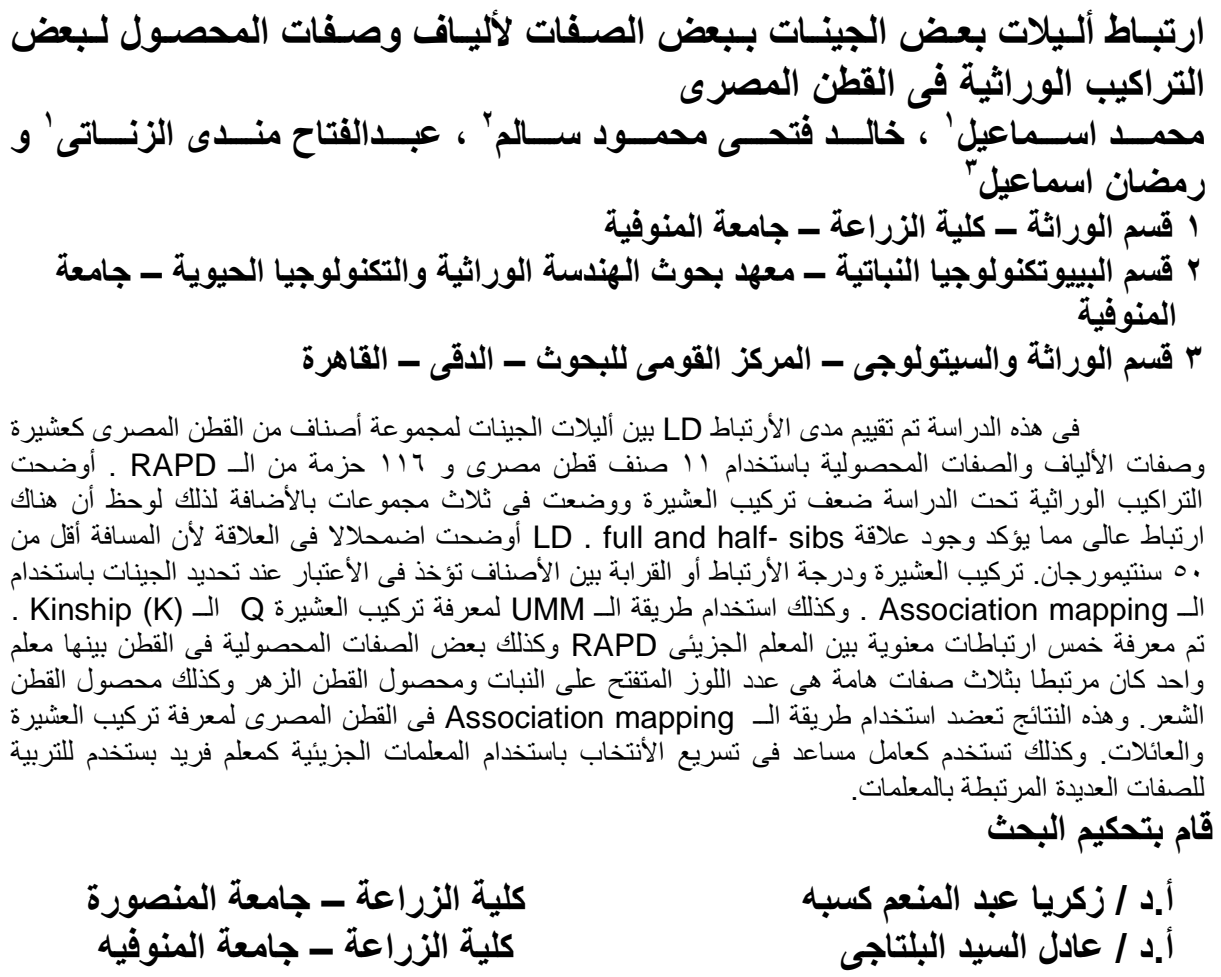

